Bulgarian Journal of Veterinary Medicine, 2019, 22, No 4, 399-408

ISSN 1311-1477; DOI: 10.15547/bjvm.2133

Original article

\title{
MOLECULAR CHARACTERISATION OF INFECTIOUS BURSAL DISEASE VIRUS (IBDV) ISOLATED FROM COMMERCIAL BROILER CHICKENS IN NILE DELTA, EGYPT
}

\author{
N. ALKHALEFA ${ }^{1}$, M. EL-ABASY ${ }^{2}$, S. $_{\text {KASEM }}{ }^{1} \&$ E. ABU EL-NAGA ${ }^{1}$ \\ ${ }^{1}$ Department of Virology, ${ }^{2}$ Department of Poultry Diseases; Faculty of Veterinary Medicine, \\ Kafrelsheikh University, Kafrelsheikh, Egypt
}

\section{Summary}

Alkhalefa, N., M. El-Abasy, S. Kasem \& E. Abu El-Naga, 2019. Molecular characterisation of infectious bursal disease virus (IBDV) isolated from commercial broiler chickens in Nile Delta, Egypt. Bulg. J. Vet. Med., 22, No 4, 399-408.

Infectious bursal disease virus (IBDV) is a highly infectious disease affecting young chickens that alters predominantly the immune system. Emergence of new variants causes severe economic losses not only in Egypt but also all over the world. For this purpose assessment of infectious bursal disease virus (IBDV) genotypes in 20 commercial broiler flocks aged 20-35 days raised in 5 provinces in the Nile Delta, Egypt (Gharbia, Dakahlya, Kafr El sheikh, Zagazig and Domietta) was carried out. All flocks were vaccinated against IBD virus. RT-PCR revealed successful amplification of 620 bp of VP2 in 17 out of 20 samples (85\%). VP2 gene nucleotide sequence analysis of six IBDV isolates (F342-1, F342-2, F342-4, F342-5 and F342-7) revealed 99.1 \% similarity to the Giza 2000, Giza $2008 \mathrm{vv}, \mathrm{SV}-\mathrm{G} 1, \mathrm{SV}-\mathrm{G} 2, \mathrm{SV}-\mathrm{G} 4$ and SV-G5 which were very virulent IBDV strains while the isolate F342-3 was close to D78 classical vaccinal strain and Kal 2001 classical IBDV strain variant.

Key words: AGID, chick embryos, IBDV, isolation, RT-PCR, sequencing, VP2

\section{INTRODUCTION}

Infectious bursal disease is an acute and highly contagious disease affecting young chickens (Sharma \& Lee, 1983). IBDV infections target the bursa of Fabricius, which is the main site for B-lymphocytes; in addition to thymus, spleen, Harderian gland, and caecal tonsils (Snyder, 1990). IBD leads to immunosuppression (Muller, 1986). Based on serological assays there are two IBDV serotypes; serotype 1 vi- ruses affect young birds and are classified as classic, variant and very virulent IBDV strains which differ in their virulence, antigenic and molecular characters. Serotype 2 viruses are usually not pathogenic (Liu et al., 2001). In Africa and Europe, very virulent IBD viruses cause high mortality rate, which may exceed 50\% (Zorman-Rojs et al., 2003). 
Molecular characterisation of infectious bursal disease virus (IBDV) isolated from commercial ...

IBDV are classified in the family Birnaviridae, genus Avibirnavirus. IBDV is a non-enveloped virus with icosahedral symmetry consisting of dsRNA genome, in the form of two segments $\mathrm{A}$ and $\mathrm{B}$ (Eterradossi \& Saif, 2008). The A segment consists of two open reading frames (ORF), one encodes for VP5 (17 kDa) which is important for viral release while the second encodes for VP243 (Wei et al., 2011). By viral protease, the polyprotein VP243 self-cleaves to form VP4 (24 $\mathrm{kDa})$, VP3 (33e35 kDa) and VP2 (48 $\mathrm{kDa}$ ) (Kibenge et al., 1988). The segment $\mathrm{B}$ encodes for an RNA-dependent RNA polymerase VP1 $(90 \mathrm{kDa})$ (Von Einem et al., 2004).

Neutralising antibodies response is elicited against the hyper variable region (HVR) of virus protein 2 which lies between $206^{\text {th }}$ and $350^{\text {th }}$ amino acid (Qi et al., 2009). IBDV strains characterisation depends up on the HVR region antigenicity, as the amino acid sequence changes in this region leads to emergence of different pathogenic variants which can overcome the host immune response (Durairaj et al., 2011). In recent years amplification of IBD virus protein (VP2) gene and comparison of genetic variation present in this region has been the major focus for strain identification (Bayliss et al., 1990; Brown et al., 1994; Wu et al., 2007).

The IBDV infection may lead to immunosuppression and limited vaccine response, increasing the chicken susceptibility to secondary bacterial infection (Heine et al., 1991). Intermediate plus strains and low virulent ones are used as IBDV vaccines, but bursal inflammation may occur with low virulent strains due to the reversion to virulent pathotype in addition to failure of birds protection against vvIBDV infections (Sapats \& Ignjatovic, 2000; Muller et al., 2003). As a result in spite of multiple vaccination strategies, severe economic losses in poultry industry in Egypt due to IBDV infection are still noted (Hassan, 2004).

Laboratory diagnosis of IBDV can be performed by virus propagation in embryonated chicken eggs (ECE). A variety of avian cell cultures such as chicken embryo fibroblast (CEF), cell cultures from the chicken embryo cloacal bursa are also used. Molecular techniques as conventional and real time PCR are of great importance role in IBDV identification (Lukert \& Davis, 1974).

This study was aimed to assess currently circulating strains of IBDV responsible for recent outbreaks in 5 provinces in the Nile Delta, Egypt (Gharbia, Dakahlya, Kafr El sheikh, Zagazig and Domietta) during 2014-2016.

\section{MATERIALS AND METHODS}

\section{Samples collection}

Twenty pooled bursae of Fabricius were collected from freshly dead and sacrificed broiler chickens aged 20-35 days, located in five provinces in the Nile Delta, Egypt (Gharbia, Dakahlya, Kafr El sheikh, Zagazig and Domietta). All the examined birds suffered from dehydration and watery diarrhoea. Post mortem examination of examined birds revealed haemorrhagic enlarged bursa, petecheal haemorrhages on thigh and pectoral muscles, swollen kidneys and ureters filled with urates. The samples were collected during the period 2014-2016, immediately transported to the lab in icebox and kept at $-70{ }^{\circ} \mathrm{C}$ till used.

\section{Virus isolation}

Pooled bursal samples were minced to form $10 \%$ suspension in sterile PBS 
(pH 7.2), containing $1 \mathrm{mg} / \mathrm{mL}$ of streptomycin sulphate, and 1000 unit $/ \mathrm{mL}$ of penicillin (Penicillin-Streptomycin - Lonza, Supplier: Lonza Walkersville INC). Suspensions were centrifuged for $15 \mathrm{~min}$ at $800 \times \mathrm{g}$ at $4{ }^{\circ} \mathrm{C}$. From each suspension, $0.1 \mathrm{~mL}$ aliquot was inoculated into three 11-day-old specific pathogen free embryonated chicken eggs (SPF ECE) (SPF production project, Fayoum, Egypt), via chorio-allantoic membrane (CAM). ECE were incubated at $37{ }^{\circ} \mathrm{C}$ for 7 days with daily candling. Any mortality within the first day post-inoculation was considered non-specific and the eggs discarded.

Agar gel immunodiffusion assay (AGID)

Ten percent suspensions of positive CAMs from inoculated ECE were used according to Lohr (1980). Briefly, a pattern of central well surrounding six peripheral wells was made in the agar medium. A total of $30 \mu \mathrm{L}$ of IBDV reference antiserum (VLDIA020-AGP-GUM, Lot no: 9706, Maf: GD) was loaded in the central well, while $30 \mu \mathrm{L}$ of antigens to be tested for precipitinogen were placed into each peripheral well. The last two wells (marked as 5 and 6) in each plate served as positive control containing IBDV antigen (VLDIA020-AGP-GUM Lot No: m03103-230903, Maf: GD) and negative control (PBS), respectively. Readings recorded after $24-48 \mathrm{~h}$, by observing the plate against dark background using indirect light source. The positive result indicated by formation of precipitin line between the antigen-antibody wells.

\section{RNA extraction}

Total RNA was extracted from the infected CAMs as well as from the lyophilised IBDV vaccine (freeze-dried live attenuated vaccine VLDIA020- AGPGUM Lot No: M03103-230903, Maf: Gd) using QIAamp viral RNA mini kit (Qiagen, Hilden, Germany) according to the manufacturer's instructions. The extracted RNAs were stored at $-20{ }^{\circ} \mathrm{C}$ for further investigations.

\section{$R T-P C R$}

cDNA was synthesised using one step RTPCR Kit (Qiagen, Germany) following the manufacturer instructions. The cDNA was further used for the amplification of VP2 gene of IBDV through gene specific forward and reverse primers VP2F5'TACCGTCCTCAGCTTACCCACATC3' and VP2R5'-GGATTTGGGATCAGCTC GAAGTTGC3' according to Metwally et al. (2009). The RT-PCR was performed in $50 \mu \mathrm{L}$ volumes, the reaction mixture consisted of $25 \mu \mathrm{L}$ of $2 \times$ RT-PCR buffer, $1 \mu \mathrm{L}$ of forward and reverse primers, $1 \mu \mathrm{L}$ RT enzyme, $1 \mu \mathrm{L} \mathrm{MgSO}_{4}, 11 \mu \mathrm{L}$ RNasefree water and $10 \mu \mathrm{L}$ RNA template. The cycling program consisted of $50{ }^{\circ} \mathrm{C}$ for $20 \mathrm{~min}, 95^{\circ} \mathrm{C}$ for $15 \mathrm{~min}, 94^{\circ} \mathrm{C}$ for $5 \mathrm{~min}$ (initial denaturation), followed by 35 thermal cycles of denaturation at $95{ }^{\circ} \mathrm{C} / 40 \mathrm{~s}$, annealing at $59{ }^{\circ} \mathrm{C} / 1 \mathrm{~min}$, extension at $72{ }^{\circ} \mathrm{C} / 1 \mathrm{~min}$ and $72{ }^{\circ} \mathrm{C}$ for $10 \mathrm{~min}$ (final extension). PCR final products were analysed by electrophoresis using a $1.5 \%$ agarose gel with $0.1 \mu \mathrm{g} / \mathrm{mL}$ ethidium bromide, and visualised by ultraviolet light transilluminator. The PCR products were purified using QIA quick Gel Extraction Kit (Qiagen Inc. Valencia CA) following the manufacturer's manual.

\section{Sequencing and phylogenetic analysis}

The purified PCR product sequenced by an Applied Bio-Systems automated DNA Sequencer (ABI, 3130, USA). Sequencing was performed using a ready reaction Bigdye Terminator V3.1 cycle sequencing kit. (Perkin-Elmer/Applied Biosystems, 
Foster City, CA). The sequence data were analysed using Clustal V multiple sequence alignment program, version 1.83 of MegAlign module of Lasergene DNA Star software Madison, WI). Phylogenic analysis was done based on the comparison of VP2 gene HVR region of the isolates with the reference strains from Gene Bank (Ndashe et al., 2016). The sequences were aligned and assembled by MEGA6 software using the Neighbor joining method (Tamura et al., 2013).

\section{RESULTS}

The virus was isolated from pooled bursal homogenates on CAM of 11-day-old SPF ECE. Seventeen out of 20 samples showed oedematous congested embryos, with hemorrhagic head and presence of gelatinous material on the skin. The embryos died at post inoculation days 3-5 (Fig. 1).

The IBDV antigen detection by the AGPT against reference IBDV antiserum revealed that 8 out of $17 \mathrm{IBDV}$ isolates were positive (Fig. 2) (samples No. 1-5, 7, 19 and 20) forming clear precipitation line.

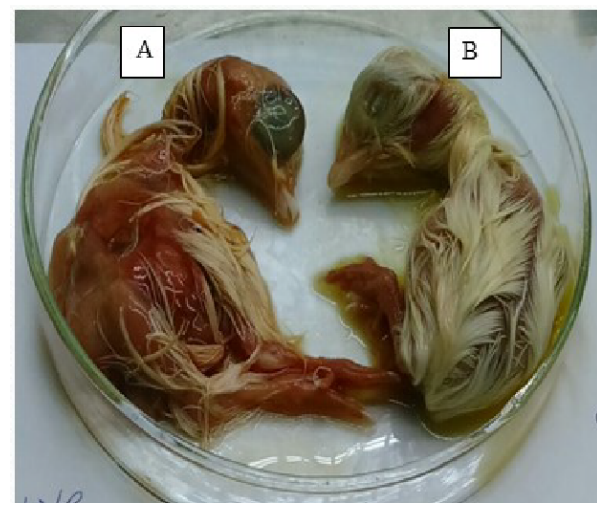

Fig. 1. 11-day-old SPF ECE inoculated with infected bursal homogenate showing haemorrhagic and oedematous embryo (A) and a normal embryo (B).

The viral RNA isolated from bursal samples showed specific amplification of VP2 gene having a size of $620 \mathrm{bp}$. Out of 20 tested samples, 18 samples were positive (Fig. 3).

The VP2 gene amplicon nucleotide sequence analysis of the five field isolates named (F342-1, F342-2, F342-4, F342-5 and F342-7), revealed $99.1 \%$ similarity to the Giza 2008 vv, SV-G1, SV-G2, SV-G4 and SV-G5 which were vvIBDV strains while the isolate F342-3 had 93.2\% simi-

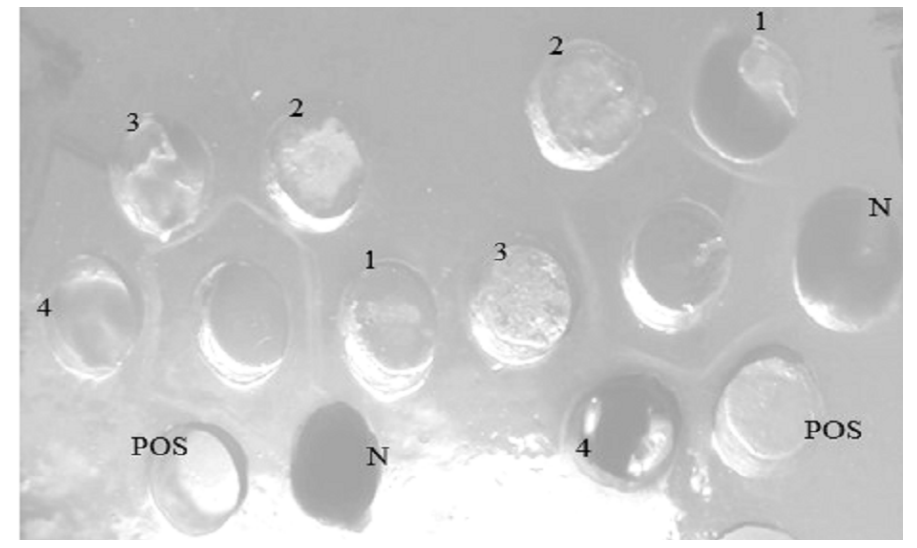

Fig. 2. AGPT of bursal homogenates: 1, 2, 3 and 4 - tested samples, POS - positive control; $\mathrm{N}$ - negative control. 


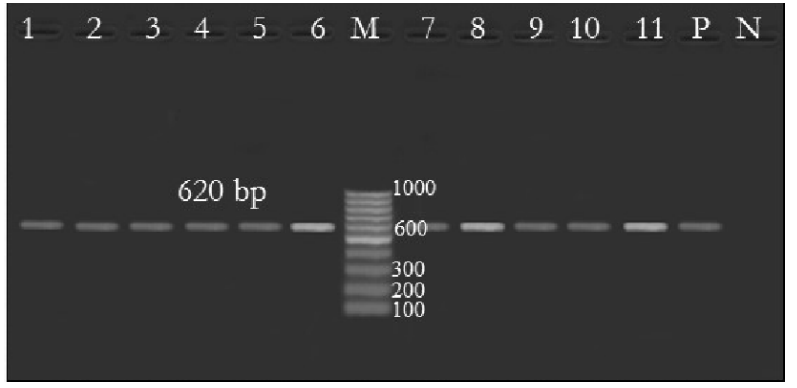

Fig. 3. Agarose gel electrophoresis of the $620 \mathrm{bp}$ RT-PCR product of the eleven isolates: lanes 1-11: the selected samples; M: DNA marker; P: positive control; N: negative control.

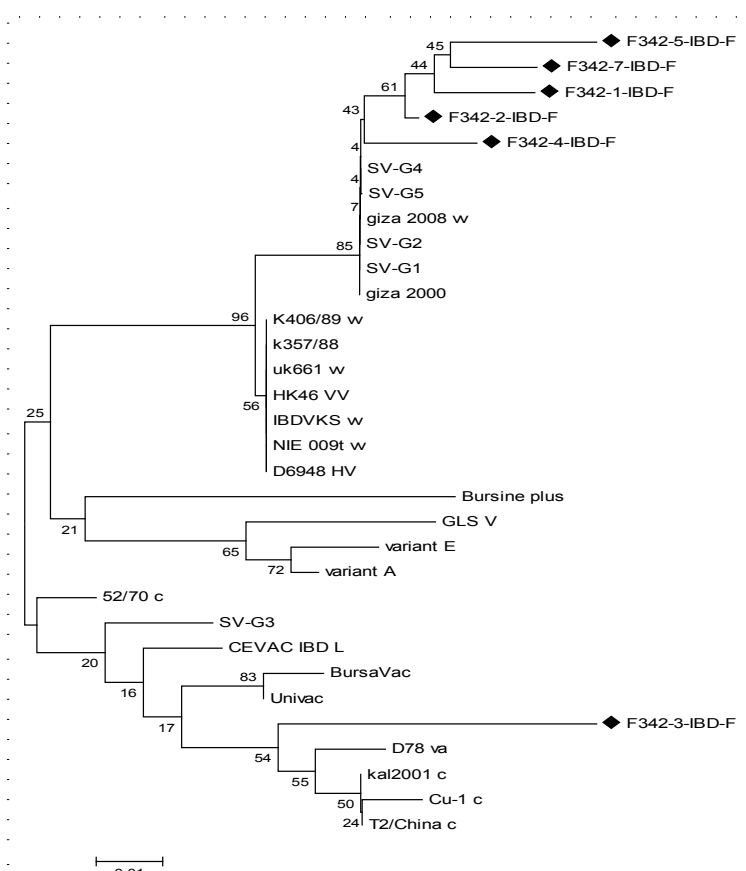

Fig. 4. Phylogenetic tree based on a partial sequence of the VP2 gene, showing the relationship between the six Egyptian IBDV isolates in the current study, the vaccinal strain present in Egypt and other reference world IBDV strains.

larity with the D78 classical vaccinal strain (Fig. 4; Table 1).

\section{DISCUSSION}

The reported outbreak confirmed positive for IBDV by the AGPT. The tissue sam- ples were collected from the ailing birds suffering from severe depression, profuse whitish diarrhoea with haemorrhagically enlarged bursa, presence of petecheae on thigh and pectoral muscles which considered to be the typical IBDV lesions as confirmed by Chettle et al. (1989) and ElBagoury et al. (2015). 
Molecular characterisation of infectious bursal disease virus (IBDV) isolated from commercial ...

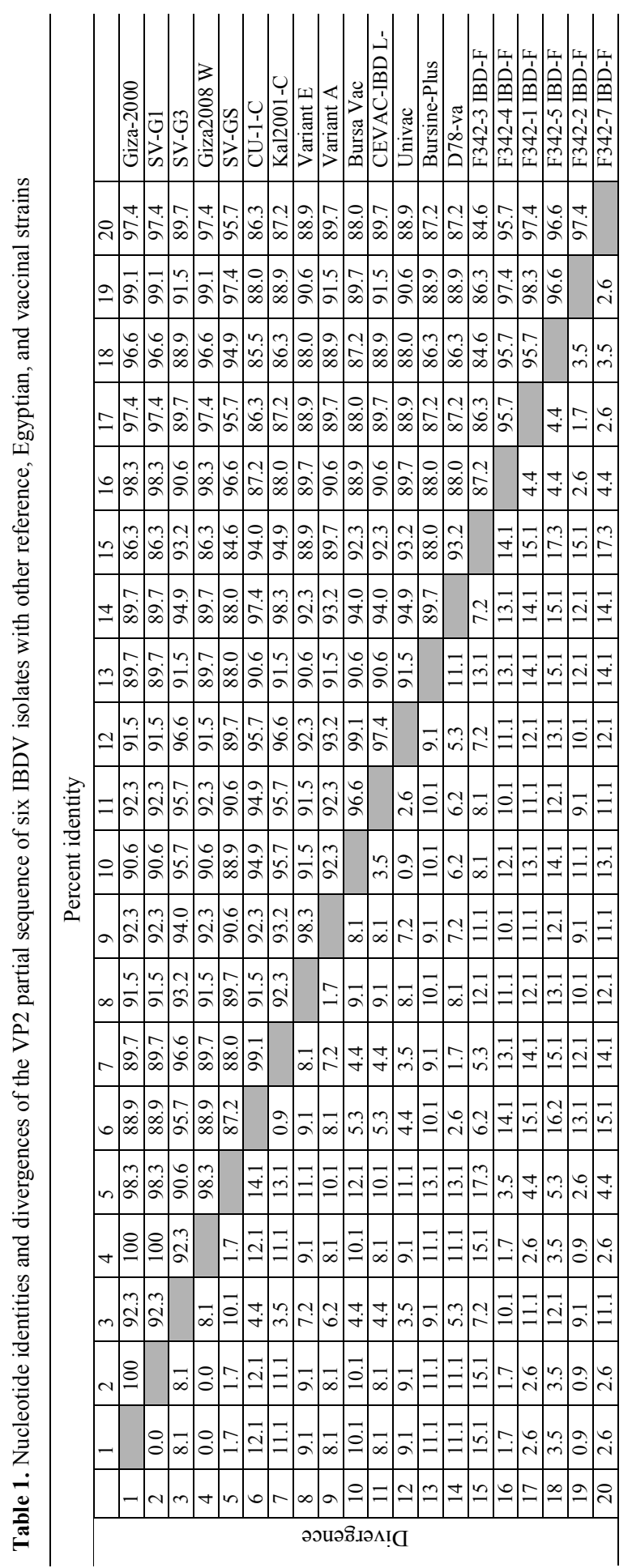


Regardless of the application of vaccination programs, the mortality rates ranged from 5 to $40 \%$, which tentatively claimed that the newly isolated IBDV strains might be able to evade the immune response produced by the traditional vaccines. Similar results were achieved by McMullin (1985) and Chettle et al., 1989) who reported that many other factors might affect the successful vaccination process including factors associated with the vaccine itself, vaccine administration, and those which are endogenous to the bird.

The viral RNA isolated from the tissue samples showed expected amplification of VP2 gene having a size of $620 \mathrm{bp}$ encoding partial sequence of its complete ORF. The phylogenetic alignment of the five selected Egyptian IBDV isolates named F342 (1, 2, 4, 5 and 7), revealed clustering in the same group with vvIBDV strains while one isolate F342-3 was close to D78 classical vaccinal strain and Kal 2001 classical IBDV strain variant (93.2\% identity). All isolates except F342-3 showed divergences than D78 reaching up to $15.1 \%$ differences. Sara et al. (2014) reported similar findings.

Amino acid identity between tested isolates and the reference strains revealed unique substitutions for amino acids at AA199 including F342-3 IBD-F serine with glycine, F342-4 IBD-F serine with cysteine, F342-5 IBD-F serine with threonine. Also there was a unique substitution at AA200 of serine with glycine at isolate F342-5 IBD-F; substitution at AA203: F342-1 IBD-F and F342-2 IBD$\mathrm{F}$, proline with histidine; F342-3 IBD-F proline with serine; F342-5 IBD-F and F342-7 IBD-F proline with threonine, strain F342-7 showed unique substitution at AA 252 of valine with isoleucine. Also at AA 215, there was a substitution for the glutamine with histidine (F342-1 \& F3427 ) and glutamine with proline (F342-5).

Virulent genetic variants of IBDV D78 have been detected following only a single point mutation at position 253(GA-1) (Brandt et al., 2001; Jackwood et al., 2008). The improper use of vaccines (i.e. reduced dose) is the driver for virulence reversion of attenuated vaccine strains (Raue et al., 2004; Martin et al., 2007; Ojkic et al., 2007; Lojkic et al., 2008). Similarly, $\mathrm{Xu}$ et al. (2011) reported that the minor difference in the HVR region resulted in immune evasion and huge outbreaks of IBDV under field conditions. The HVR region of the VP2 gene of Egyptian isolates of IBDV showed antigenic variations, suggesting the emergence of IBDV strains that can evade the host immune response. In Egypt, both vvIBDV strains and variant IBDV strains were reported and have been a serious problem circulating in flocks vaccinated using classical IBDV vaccines (Helal et al., 2012; Mohamed et al., 2014; Sara et al., 2014). Various AA substitution markers of vvIBDV such as serine rich heptapeptide in tested isolates suggested the very virulent nature of the isolates.

Poultry is the major protein source largely consumed in different areas of Egypt. The inadequate vaccination, lack of cold storage between vaccine production and administration, and improper management practices are the primary reasons of vaccination failure in Egypt. The sero surveillance and epidemiology of IBDV from Egypt has not been completely documented, making its control measures a hard task. Our knowledge of IBDV antigenic variants and its pathogenicity has exponentially increased due to availability of modern molecular biology tools. However, it will be interesting to analyse the complete genome sequence 
Molecular characterisation of infectious bursal disease virus (IBDV) isolated from commercial ...

of more and more IBDV strains from Egypt in order to define the molecular markers of its circulating strains.

In conclusion, the present study successfully characterised five very virulent IBDV strains and one classical strain from field cases of IBD. Further investigations to establish new vaccination strategies to prevent the current IBDV infection are needed.

\section{REFERENCES}

Bayliss, C. D., U. Spies, K. Shaw, R. W. Peters, A. Papageorgiou, H. Müller \& M. E. G. Boursnell, 1990.A comparison of the sequences of segment $\mathrm{A}$ of four infectious bursal disease virus strains and identification of a variable region in VP2. Journal of General Virology, 71, 1303-1312.

Brandt, M., K. Yao, M. Liu, R. A. Heckert \& V. N. Vakharia, 2001. Molecular determinants of virulence, cell tropism, and pathogenic phenotype of infectious bursal disease virus. Journal of Virology, 75, 11974-11982.

Brown, M. D., P. Green \& M. A. Skinner, 1994. VP2 sequences of recent European 'very virulent' isolates of infectious bursal disease virus are closely related to each other but are distinct from those of "classical' strains. Journal of General Virology, 75, 675-680.

Chettle, N., J. C. Stuart \& P. J. Wyeth, 1989. Outbreak of virulent infectious bursal disease in East Anglia. The Veterinary Record, 125, 271-272.

Durairaj, V. H., S. Sellers, E. G. Linnemann, A. H. Icard \& E. Mundt, 2011. Investigation of the antigenic evolution of field isolates using the reverse genetics system of infectious bursal disease virus (IBDV), Archives of Virology, 156, 1717-1728.

El-Bagoury, G. F., A. F. Nada, A. El-Habbaa \& A. A. Abu-Zied, 2015. Molecular characterization of IBD virus isolated from
Giza governorate, Egypt, 2014. Benha Veterinary Medical Journal, 28, 223-234.

Eterradossi, N. \& Y. M. Saif, 2008. Infectious bursal disease. In: Diseases of Poultry, $12^{\text {th }}$ edn, eds Saif, Y. M., A. M. Fadly, J. R. Glisson, L. R. McDougald, L. K. Nolan, D. E. Swayne, Wiley-Blackwell, Ames, IA, USA, pp. 185-208.

Hassan, M. K., 2004. Very verulent infectious bursal disease virus in Egypt: epidemiology, isolation and immunogenicity of classic vaccine. Veterinary Research Communications, 28, 347-356.

Heine, H. G., M. Haritou, P. Failla, K. Fahey \& A. Azad, 1991. Sequence analysis and expression of the host-protective immunogen VP2 of a variant strain of infectious bursal disease virus, which can circumvent vaccination with standard type, I strains. Journal of General Virology, 72, 18351843.

Helal, A. M., S. S. El-Mahdy \& M. A. Afify, 2012. Study on the prevalence of variant IBD strains in some Egyptian chicken farms. New York Science Journal, 5, 8-11.

Jackwood, D. J., B. Sreedevi, L. J. LeFever \& S. E. Sommer-Wagner, 2008. Studies on naturally occurring infectious bursal disease viruses suggest that a single amino acid substitution at position 253 in VP2 increases pathogenicity. Virology, 377, 110-116.

Kibenge, F. S. B., A. S. Dhillon \& R. G. Russell, 1988. Biochemistry and immunology of infectious bursal disease virus. Journal of General Virology, 69, 1757-1775.

Liu, H. J., P. H. Huang, Y. H. Wu, M. Y. Lin \& M. H. Liao, 2001. Molecular characterization of very virulent infectious bursal disease viruses in Taiwan. Research in Veterinary Science, 70, 139-147.

Lohr, J. E., 1980. Infectious bronchitis agargel precipitin test - use of infected allantoic fluid as antigen. Avian Diseases, 24, 463-467.

Lojkic, I., Z. Bidin \& B. Pokric, 2008. Sequence analysis of both genome segments of three Croatian infectious bursal disease 
field viruses. Avian Diseases, 52, 513 519.

Lukert, P. D. \& R. B. Davis, 1974. Infectious bursal disease virus: Growth and characterization in cell cultures. Avian Diseases, 18, 243-250.

Martin, A. M., F. Fallacara, I. Barbieri, G. Tosi, G. Rivallan, N. Eterradossi, R. Ceruti \& P. Cordioli, 2007. Genetic and antigenic characterization of infectious bursal disease viruses isolated in Italy during the period 2002-2005. Avian Diseases, 51, 863-872.

McMullin, P., 1985. Factors, which interfere with vaccine efficacy. In: Proceedings of the 1st Sta. Catarina Poultry Symposium, pp. 10-20.

Metwally, A. M., A. A. Yousif, I. B. Shaheed, W. A. Mohammed, A. M. Samy \& I. M. Reda, 2009. Re-emergence of very virulent IBDV in Egypt. International Journal of Virology, 5, 1-17.

Mohamed, M. A., K. E. S. Elzanaty, B. M. Bakhit \& M. M. Safwat, 2014. Genetic characterization of infectious bursal disease viruses associated with gumboro outbreaks in commercial broilers from Assiut province, Egypt. ISRN Veterinary Science, http://dx.doi.org/10.1155/2014/916412.

Muller, H., 1986. Replication of infectious bursal disease virus in lymphoid cells. $A r$ chives of Virology, 87, 191-203.

Muller, H., M. R. Islam \& R. Raue, 2003. Research on infectious bursal disease - the past, the present and the future. Veterinary Microbiology, 97, 153-165.

Ndashe, K., E. Simulundu, B. M. Hang'ombe, L. Moonga, H. Ogawa \& A. Takada, 2016. Molecular characterization of infectious bursal disease viruses detected in vaccinated commercial broiler flocks in Lusaka, Zambia. Archives of Virology, 161, 513519.

Ojkic, D., E. Martin, J. Swinton, B. Binnington \& M. Brash, 2007. Genotyping of Canadian field strains of infectious bursal disease virus. Avian Pathology, 36, $427-$ 433.
Qi, X., H. Gao, Y. Gao, L. Qin, Y. Wang \& L. Gao, 2009. Naturally occurring mutations at residues 253 and 284 in VP2 contribute to the cell tropism and virulence of very virulent infectious bursal disease virus, Antiviral Research, 84, 225-233.

Raue, R., M. R. Islam, M. N. Islam, K. M. Islam, S. C. Badhy, P. M. Das \& H. Muller, 2004. Reversion of molecularly engineered, partially attenuated, very virulent infectious bursal disease virus during infection of commercial chickens. Avian $\mathrm{Pa}$ thology, 33, 181-189

Sapats, S. I. \& J. Ignjatovic, 2000. Antigenic and sequence heterogeneity of infectious bursal disease virus strains isolated in Australia. Archives of Virology, 145, 773-785.

Sara, A. M., A. Arafa \& A. Hussein, 2014. Molecular genotyping of the infectious bursal disease virus (IBDV) isolated from broiler flocks in Egypt. International Journal of Veterinary Science and Medicine, 2, 46-52.

Sharma, J. M. \& L. F. Lee, 1983. Effect of infectious bursal disease on natural killer cell activity and mitogenic response of chicken lymphoid cells: Role of adherent cells in cellular immune suppression. Infection and Immunity, 42, 747-754.

Snyder, D. B., 1990. Changes in the field status of infectious bursal disease virus. Avian pathology, 19, 419-423.

Tamura, K., G. Stecher, D. Peterson, A. Filipski \& S. Kumar, 2013. MEGA6: Molecular Evolutionary Genetics Analysis version 6.0. Molecular Biology and Evolution, 30, 2725-2729.

Von Einem, U. I., A. E. Gorbalenya, H. Schirrmeier, S. E. Behrens, T. Letzel \& E. Mundt, 2004. VP1 of infectious Bursal disease virus is an RNA-dependent RNA polymerase. Journal of General Virology, 85, 2221-2229.

Wei, L., L. Hou, S. Zhu, J. Wang, J. Zhou \& J. Liu, 2011. Infectious bursal disease virus activates the phosphatidylinositol 3-kinase (PI3K)/Akt signaling pathway by interac- 
Molecular characterisation of infectious bursal disease virus (IBDV) isolated from commercial ...

tion of VP5 protein with the p85alpha subunit of PI3K. Virology, 417, 211-220.

Wu, C. C., P. Rubinelli \& T. L. Lin, 2007. Molecular detection and differentiation of infectious bursal disease virus. Avian Diseases, 51, 515-526.

Xu, X. G., D. W. Tong, Z. S. Wang, Q. Zhang, Z. C. Li \& K. Zhang, 2011. Baculovirus virions displaying infectious bursal disease virus VP2 protein protect chickens against infectious bursal disease virus infection. Avian Diseases, 55, 223-229.

Zorman-Rojs, O., D. Barlic-Maganja, D. Mitevski, W. Lubke \& E. Mundt, 2003. Very virulent infectious bursal disease virus in southeastern Europe. Avian Diseases, 47, 186-192.
Paper received 07.01.2018; accepted for publication 16.03.2018

\section{Correspondence:}

Noura Alkhalefa

Veterinary Virology Department,

Faculty of Veterinary Medicine,

Kafrelshikh University,

33516, Elgeish street,

Kafrelsheikh, Egypt,

tel/fax: +2-047-323-1311;

e-mail: nora_fysal2007@yahoo.com, noura_fysal@vet.kfs.edu.eg 